\title{
Advanced Optimization Design of Cross Beams Structure
}

\author{
Ke Zhang, Xuan Mu*, Dehong Zhao and Yuhou Wu
}

School of Traffic and Mechanical Engineering, Shenyang Jianzhu University Shenyang China, 100168

\begin{abstract}
Solid Isotropic Microstructure with Penalization(SIMP) in topology optimization was deeply analyzed, and thus SIMP topology optimization criteria algorithm was deduced. Simulation analysis to the results was also conducted by Ansys, so as the structural lightweight design to machine crossbeams of the HTM series gantry. By verifying, the structure was $3.8 \%$ lower than the traditional structure quality, stiffness increased by $16.07 \%$, and the overall inherent frequency was improved. By applying topology optimization method to the design process of the machining center HTM series, material utilization is improved and production costs were reduced.
\end{abstract}

Keywords: Cross beams, SIMP, topological optimization paper specification.

\section{INTRODUCTION}

With the development of mechanical science, the new demands on the mechanical design are; how to improve the utilization of materials and reduce the manufacturing costs of the machine. So, it is important to optimize the design of the structure and components of the machine tools. The common method of optimization includes topological optimization, shape optimization and size optimization. Topological optimization is a higher level of structural optimization, it is carried out by the topology information, such as the layout of the nodes and the connections between nodes of structure of bar system or the number and location of the open pores of continuum structure [1]. Z.Y. Jia and X.Y. Wang in Dalian University of Technology carried out the topology optimization study to the cross beam of gantry machining center by using ICM method, and the final crossbeam is 6\% lighter than original [2]. The guide-weight method and its Lagrange multipliers' solution methods are presented by Jun Xin Liu and Zhi Dong LI, then the iterative formulas of the guideweight method are derived and the guide-weight method is used to solve topology optimization problems with multiple loads [3]. X. Huang, Z.H. Zuo and Y.M. Xie in Australia presented a modified SIMP model which produced a new bidirectional evolutionary structural optimization (BESO) method combined with rigorous optimality criteria, and it is developed for topology frequency optimization problems [4].

The cross beam of gantry machine is an important part which plays the role of supporting the working head of the saddle and connecting the key components, such as the column and the lathe bed. It also realizes the longitudinal feed of the machining center by driving the working head in the

*Address correspondence to this author at the School of Traffic and Mechanical Engineering, Shenyang Jianzhu University China;

Tel: 13889118546; E-mail: muxuan__tgl@163.com beam Drives the working head achieve the longitudinal direction of the machining center feed in the machining process. Therefore, the dynamic characteristics of the cross beam will directly affect the precision of the machine. The gantry milling machining center (HTM50200) is an eight axis five linkage CNC machining center which is developed specifically for machining complex shaped stone products, as shown in Fig. (1). The center is equipped with dual working head of milling and tuning as well as double table of upright and horizontal. Its processing ranges: the plan products are $200 \mathrm{~mm}$ $\times 200 \mathrm{~mm} \times 40 \mathrm{~mm}$ : the rotating body products are $\Phi 500 \mathrm{~mm} \times 200 \mathrm{~mm}$ : the beam span is $600 \mathrm{~mm}$ : the highest translational speed is $10 \mathrm{~m} / \mathrm{min}$.

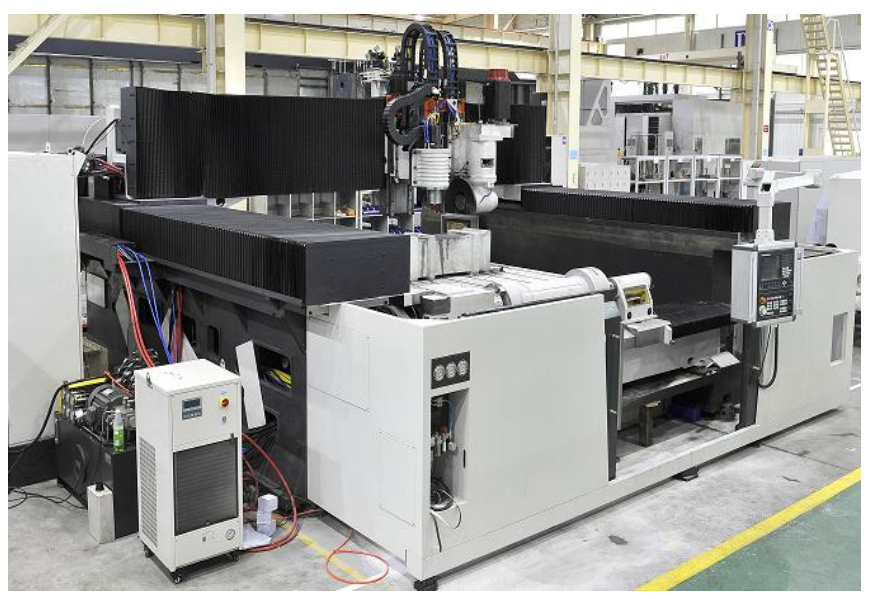

Fig. (1). The shaped stone turning-milling compound machine center (HTM50200).

Traditional auxiliary holes and rid plates adopted the homogenization symmetric structure. This layout often has a great structural redundancy of large cross beam mass and not enough stiffness, as shown in Fig. (2). In this paper, although the beam applied double linear guides form: the above rail 
was arranged horizontally and the below rail was arranged vertically, which could effectively bear the load from the saddle and the working head in the vertical and in the horizontal direction. To some extent, double linear guides improved the stiffness, but there were also the above-mentioned drawbacks. Therefore, the gantry beam was analyzed by topology optimization method based on its mechanical characteristics, and re-layout the auxiliary holes. The overall mass of the beam has been controlled and the stiffness of the beam has been improved, so as to achieve the maximum utilization of the material.

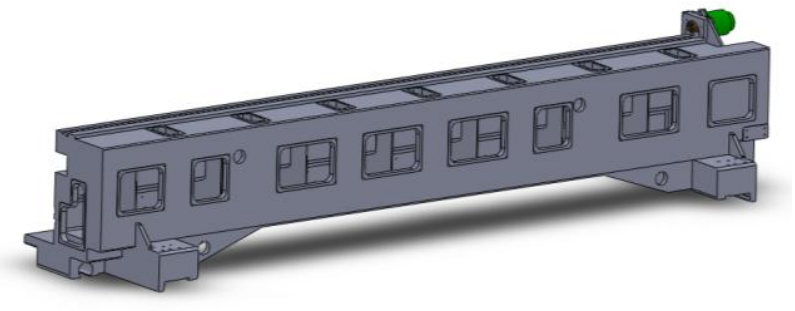

Fig. (2). The original cross beam structure of HTM50200.

\section{THE ESTABLISHMENT OF MATHEMATICAL MODEL}

\subsection{The Concept of Topology Optimization}

Structure optimization design is to replace the traditional design with the systemic and goal orientated processes and methods. Its purpose is to seek both economical and applicable structural style for a minimum of material, the lowest cost to achieve the best performance of the structure, including topological optimization, shape optimization and size optimization [1]. Topology optimization, also known as structural layout, is an important part of the structure optimization. The optimization method of seeking the optimal allocation of structural materials according to the constraints, the loads as well as optimization goals [5].The basic idea is re-planning the layout of materials in the given region of the design to achieve the designer's particular requirements. It is a conceptual design and is used in the initial design phase. For machine tools, according to certain objective function and constraints in the actual operating conditions, determine the optimal structure of the parts within the design area to achieve the purposes of improving the dynamic and static performance of the machine tools.

\subsection{Topology Optimization Mathematical Model}

Solid Isotropic Material with Penalization (SIMP) is the widely used material interpolation methods in the topology optimization method. Its core idea is an imaginary variable density material introduced artificially whose relative density is correspond to the elastic modulus of the material. The SIMP technique directly regards each of the element's material density as the design variable which may change continuously from 0 (void) to 1 (solid). At the same time, the properties of intermediate densities are penalized artificially relative to the objective function, such as the SIMP model of the minimum compliance issues [4].
An optimization problem can be expressed as shown in Eq. (1)

$$
\left\{\begin{array}{l}
\text { find }: X=\left[x_{1}, x_{2}, \ldots \mathrm{x}_{\mathrm{N}}\right]^{t} \\
\min f(x) \\
\text { s.t. } g(x)=\left[g_{1}(x), g_{2}(x), \ldots g_{n}(x)\right]
\end{array}\right.
$$

In the above formula, the design variable $x_{i}$, the objective function $f(x)$ and the state variable $g(x)$ are three elements of the mathematical model of the structure optimization.

It regarded the stiffness of the whole structure to maximum which is equivalent to the total deformation of the structure to minimum as the target and the volume of material as constraint condition to establish the design model of topology optimization [6]. The corresponding optimization problem can be stated as shown in Eq. (2):

$\left\{\begin{array}{l}\text { find }: X=\left[x_{1}, x_{2}, \ldots \mathrm{x}_{\mathrm{N}}\right]^{t} \\ \min : C=F^{T} u \\ \text { s.t }: V(x)=f V_{0} \leq V^{*} \\ F=K u \\ 0<x_{\min } \leq x \leq 1\end{array}\right.$

Where $\mathrm{C}$ represents the complaisant spend of the structure and, is the design variable which represents the relative density of the material. $F$ is the load vector and $u$ is the nodal displacement vector. $\mathrm{N}$ represents the total numbers of units and is the initial volume of the entire design domain. $f$ is the optimized volume ratio. $\mathrm{K}$ is the overall stiffness matrix. $\mathrm{V}^{*}$ is the maximum volume, $\mathrm{V}(\mathrm{x})$ is the volume of the optimized structure.

The relational expression based on the SIMP method based topology optimization is shown in Eqs. (3) and (4)

$$
\begin{aligned}
& E=\left(x^{e}\right)^{p} E_{0} \\
& K_{e}=\left(x^{e}\right)^{p} K_{0}
\end{aligned}
$$

Where $E_{0}$ represents unit initial elastic modulus and $\mathrm{E}$ is the optimized elastic modulus. $k_{0}$ represents the initial stiffness matrix and $k_{e}$ is the optimized stiffness matrix. $\mathrm{p}$ is the penalty factor which is the penalty factor intermediate density unit items punishment to try to reduce the number of unit structure of intermediate density. So that the density of the structural unit is as much as possible approach to 0 or 1 .

The relational expression of finite element structure is shown in Eq. (5):

$$
V(x)=f V_{0}=\sum_{e=1}^{N} x^{e} v^{e}
$$

Where $v^{e}$ represents optimized unit volume and $x_{e}$ is unit design variables. And, the compliance can be written as shown in Eq. (6) 
$C=F^{T} U=U^{T} K U=\sum_{i=1}^{N} u^{e T} k^{e} u^{e}=\sum_{e=1}^{N}\left(x^{e}\right)^{p} u^{e T} k^{e} u^{e}$

The mathematical model can be written as shown in Eq. (7) relationships under the SIMP.

$$
\left\{\begin{array}{l}
\min : C=F^{T} u=U^{T} K U=\sum_{i=1}^{N} u^{e T} k^{e} u^{e}=\sum_{e=1}^{N}\left(x^{e}\right)^{p} u^{e T} k^{e} u^{e} \\
\text { s.t }: V(x)=f v_{0}=\sum_{e=1}^{N} x^{e} v^{e} \leq V^{*} \\
F=K u \\
0<x_{\min } \leq x^{e} \leq 1
\end{array}\right.
$$

The optimality criteria (OC) is generally applicable to single target, single constrained optimization problem, it has the high calculation speed, and the calculated scale is unrelated with the number of unknown variables.

Constructing the Lagrangian function for the optimization problem the equation can be written as shown in Eq. (8)

$L=C+\lambda_{1}\left(V-V^{*}\right)+\lambda_{2}(F-K U)+\lambda_{3}\left(x_{\min }-x\right)+\lambda_{4}(x-1)(8)$

Where, $\lambda_{1}, \lambda_{2}, \lambda_{3}, \lambda_{4}$ are Lagrange multipliers, select the extreme value when $x=x^{*}$, Kuhn-Tucker Lagrangian function should satisfy the necessary conditions, for the optimization problem the equation can be written as shown in Eq. (9)

Because the external load $\mathrm{F}$ is a fixed load and does not vary with the change of density, so $\frac{\partial F}{\partial x^{*}}=\frac{\partial(K U)}{\partial x^{*}}=10$. when $x_{\min } \leq x^{*} \leq x_{\max }$ the minimum and maximum are useless, so $\lambda_{3}=0, \lambda_{4}=0$; when $x^{*}=x_{\min }$ the minimum are useless so $\lambda_{3}=0$; When $x^{*}=x_{\max }$ the maximum are useless $\lambda_{4}=0$. The Kuhn-Tucker can be rewritten as Eq. (10)

$$
\left\{\begin{array}{l}
\frac{\partial L}{\partial x_{i}}=\frac{\partial c}{\partial x_{i}}+\lambda_{1} \frac{\partial V}{\partial x_{i}}-\lambda_{2} \frac{\partial(K U)}{\partial x_{i}}+\lambda_{3} \\
V=V^{*} \\
F=K U \\
\lambda_{3}\left(x_{\min }-x^{*}\right)=0 \\
\lambda_{4}\left(x^{*}-1\right)=0 \\
\left.\lambda\right|_{x=x^{*}} \geq 0 \\
x_{\min } \leq x^{*} \leq 1
\end{array}\right.
$$

$$
\begin{cases}\frac{\partial L}{\partial x_{i}}=\frac{\partial c}{\partial x_{i}}+\lambda_{1} \frac{\partial V}{\partial x_{i}}-\lambda_{2} \frac{\partial(K U)}{\partial x_{i}} & \left\{\begin{array}{l}
=0\left(x_{\min }<x^{*} \leq 1\right) \\
>0\left(x^{*}=x_{\min }\right) \\
\\
V=V^{*}
\end{array}\right. \\
K U=F & \\
\left.\lambda\right|_{x=x^{*}} \geq 0 & \end{cases}
$$

The case of the above equation is equal to 0 , and further optimization criterion is $B=\frac{-\partial c / \partial x}{\lambda \partial v / \partial x_{i}}=1$, the model can be written as shown in Eq. (11)

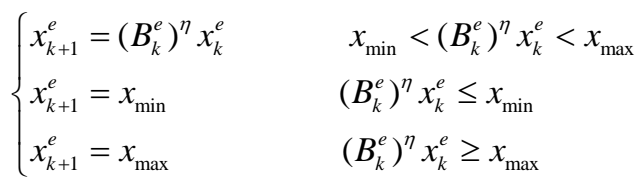

\section{TOPOLOGY OPTIMIZATION ANALYSIS OF CROSS BEAM OF THE CNC}

Three-dimensional modeling of gantry beams with Solid Works has been established. According to Saint-Venant prin-

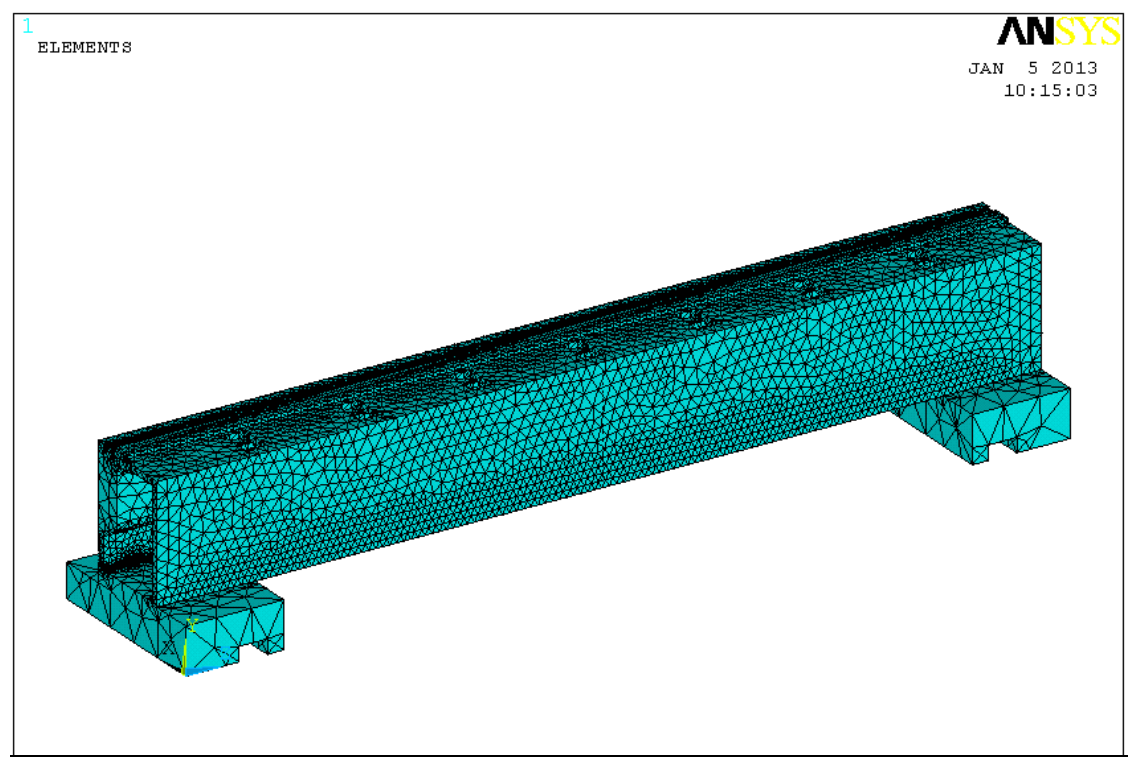

Fig. (3). Initial design area. 
ciple [7], chamfering, screw holes and some of the smaller size holes have been appropriate simplified and even ignored.

\subsection{Initial Design Area}

To insert "Tables" or "Figures", please paste the data as stated below. All tables and figures must be given.

In order to maximize guarantee of the completeness of the physical model, the PARA format 3D model can import ANSYS through the interface belonging to SolidWorks and ANSYS. The material is assumed with Young's modulus $\mathrm{E}=1.1 \times 10^{11} \mathrm{~Pa}$, Poisson's ratio $\mathrm{v}=0.28$, and mass density $p=7850 \mathrm{~kg} / \mathrm{m}^{3}$. Its mesh size is defined and then the seven mesh divided. The Initial design area is shown in Fig. (3).

\subsection{Applied Loads and Constraints}

The gantry machine beam withstands complex space loads during work. There are the cutting force generated in the processing, self-gravity, the friction between the guide surface in the relative movement of the moving member and the fixed member, inertial force, impact or vibration disturbing force as well as the thermal stress generated when the temperature is elevated [1]. The machine tool under normal load conditions should be set in the optimization process. Therefore, the beam withstands its own gravity, gravity of the saddle and the working head. Gravity was loaded on two rails of the cross beam and the joint surface between the beam and columns is set to constraints.

\subsection{Analysis of Topology Optimization Results}

According to the actual working conditions of the beam, this paper selected multiple load conditions do topology optimization, they are the three conditions that the cross beam moves to the middle and the limiting positions on both sides of right and left. Definition intended to save $50 \%$ of the material, and the convergence tolerance of 0.0001 . The density

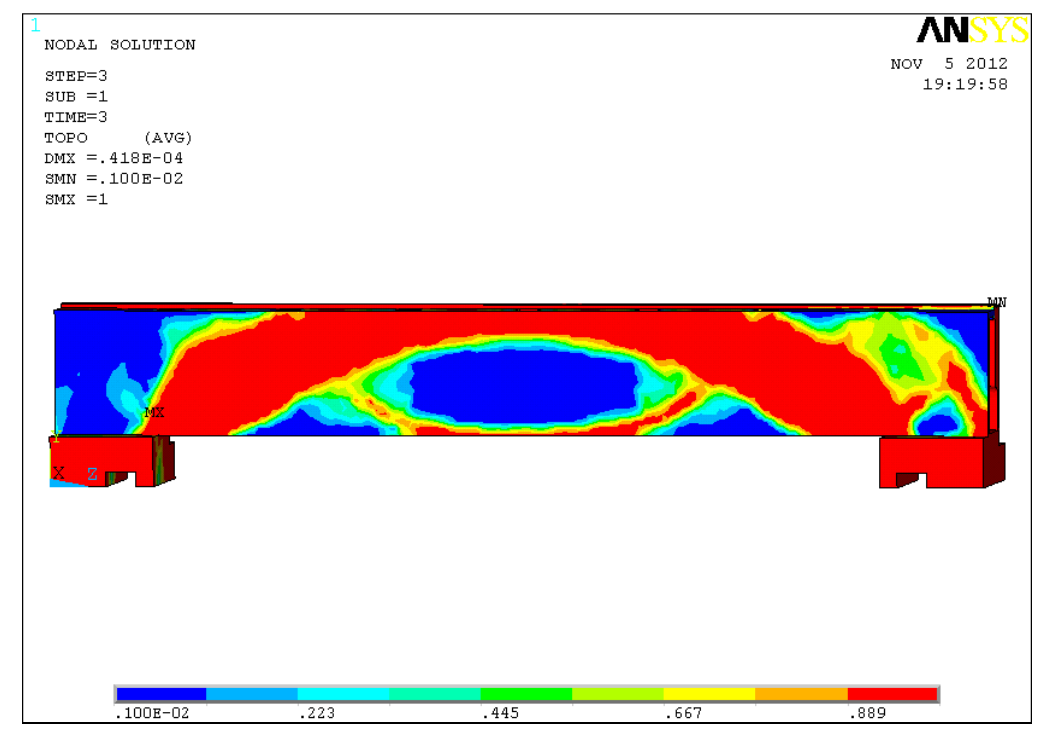

Fig. (4). Topology optimization model.

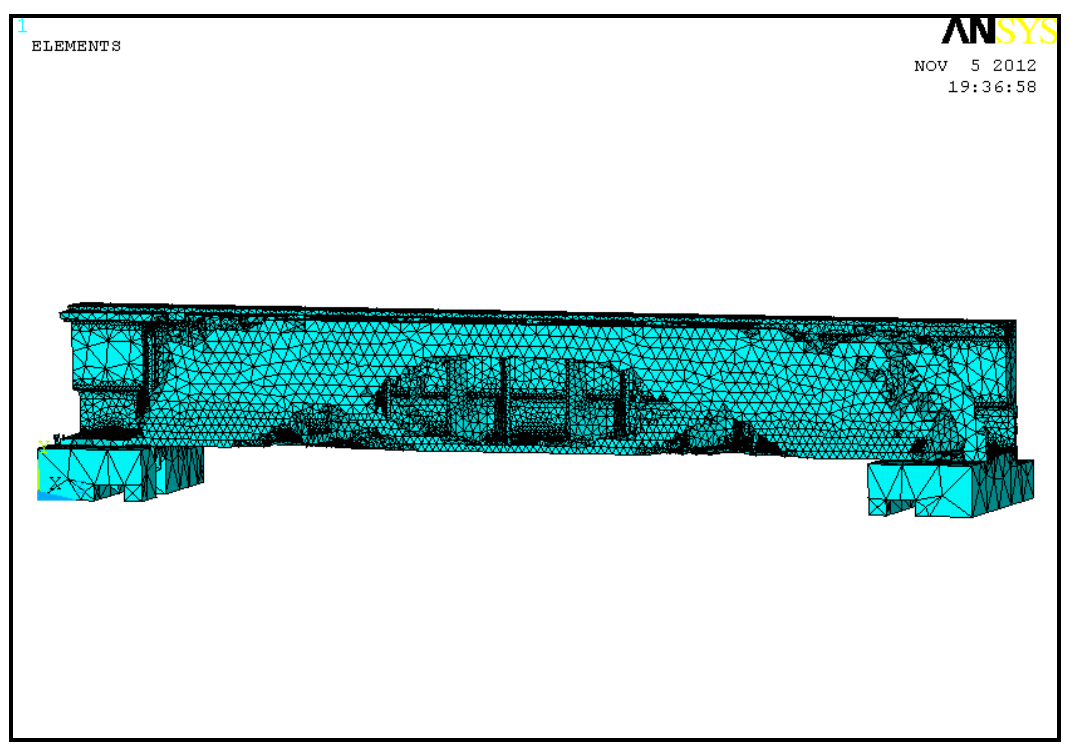

Fig. (5). Optimization model after processing. 
cloud images of the optimization results obtained from ANSYS post-process are shown in Fig. (4).

It can be seen from Fig. (4) that the red areas in density chart are the regions that density value is close to 1 , they indicate the areas that should be retained in the structure design. The blue areas are the areas that the density value is 0.001 and should be deleted in the structure design. In addition, there are some color regions between the two values, they should be necessarily processed and classified as the above two values. The processing method was to take a threshold during the density cloud images display, it was not displayed when the density was less than the threshold value and it was only displayed when the density was greater than or equal to the threshold value [8]. This paper chose the threshold value of 0.7 , and the structure after processing is shown in Fig. (5).

Dynamic and Static Analysis of the Cross Beam Before and After Optimization. Topology optimization is the conceptual design stage of the structure, its purpose is to provide optimization of regional and configuration for afterward detailed sizes. Taking the craft into consideration, the longitudinal section of the optimized cross beam has been made a small amount of process modifications. It also did the comparative analysis of static and modal to the cross beam before and after the modifications. It is measured out by SolidWorks that the mass was reduced to $9117732 \mathrm{~g}$ from $9377038 \mathrm{~g}$ before the improvements, and achieved a $2.76 \%$ reduction in the mass of the cross beam. The maximum deformations measured by ANSYS were both at the middle part, as shown in Fig. (6). However, the maximum deformation after optimization was reduced to $0.047 \mathrm{~mm}$ from $0.056 \mathrm{~mm}$ before modification. So, the deformation has achieved a $16.07 \%$ reduction, which indicates that the stiffness of the cross beam has been increased.

Modal analysis is used to determine the natural vibration characteristics of design of the structure or machine parts. Its natural frequency and mode shapes are important parameters of the structural design of withstanding dynamic loads. The main task of mode analysis is to study the no damping coefficient of free vibration, and makes designers avoid these frequencies or minimize the incentive on these frequencies, and thus eliminate the excessive vibration or noise [9]. Fig . (7) has shown the analysis results of the original design cross beam and Fig. (8) has shown the analysis results of the optimized cross beam.

It can be seen from the analysis results that the deformations of first-order and second-order are not large, and they both mainly bend upward of the central cross beam. The cross beam appeared wavy swing when the frequency was higher. From Table 1, the natural frequencies of the improved cross beam have certain increases than original beam besides the first-order. According to $\omega_{\pi}=\left(k_{\pi} / m_{\pi}\right)^{1 / 2}\left(\omega_{\pi}\right.$ represents the natural frequency of the $\mathrm{n}^{\text {th }}$ order, $\mathrm{k}_{\pi}$ and $m_{\pi}$

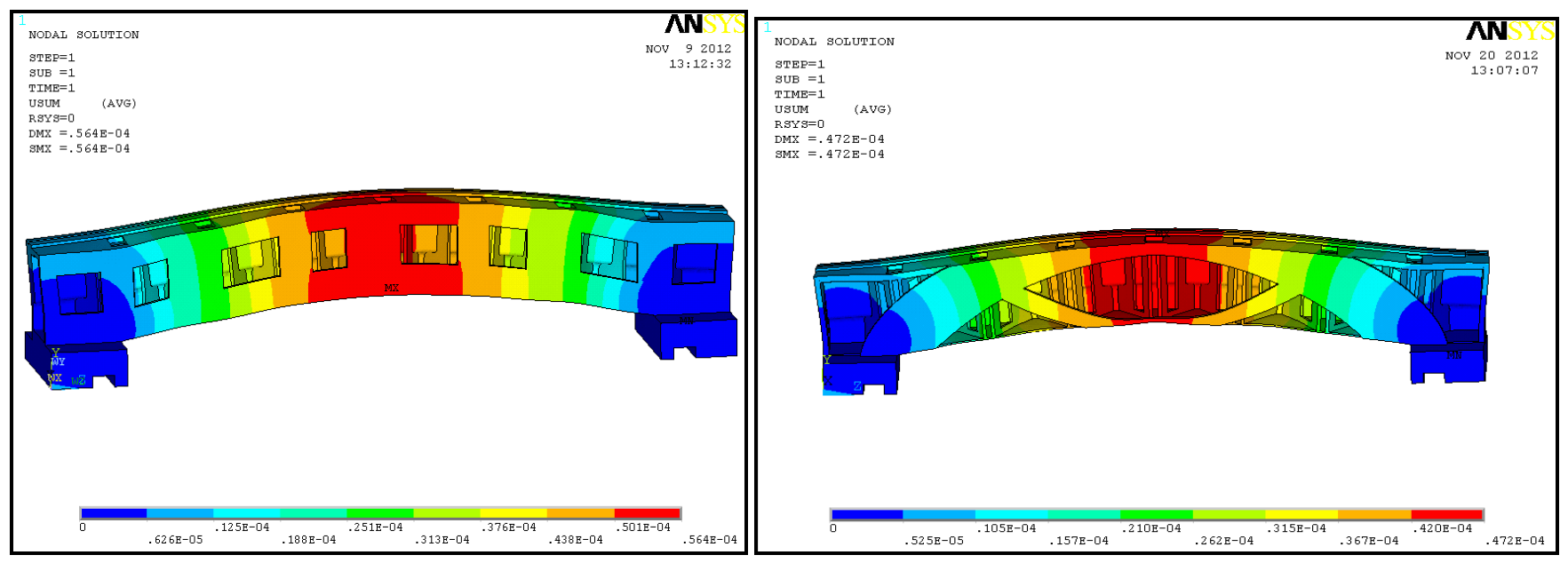

Fig. (6). Maximum deformation contrast of before and after optimization.

Table 1. The results contrast of before and after optimization of the cross beam.

\begin{tabular}{|c|c|c|}
\hline Esonance Frequency/HZ & The Original Structure & Optimization Structure \\
\hline \hline First-order & 50.232 & 49.219 \\
\hline Second-order & 77.350 & 83.315 \\
\hline Third-order & 98.082 & 114.12 \\
\hline Fourth-order & 101.59 & 131.41 \\
\hline Fifth-order & 134.96 & 171.66 \\
\hline Sixth-order & 165.60 & 199 \\
\hline
\end{tabular}




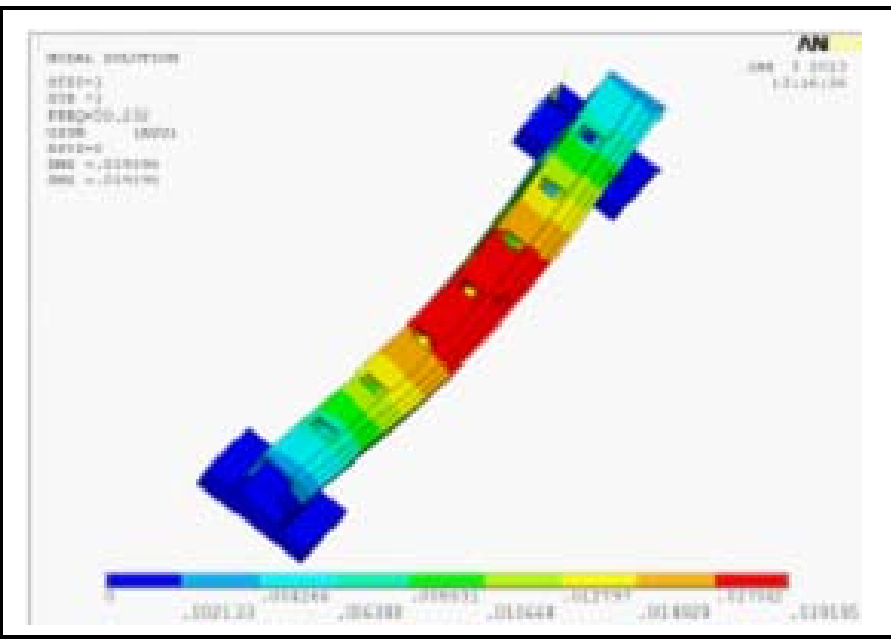

(a) First-order vibration mode

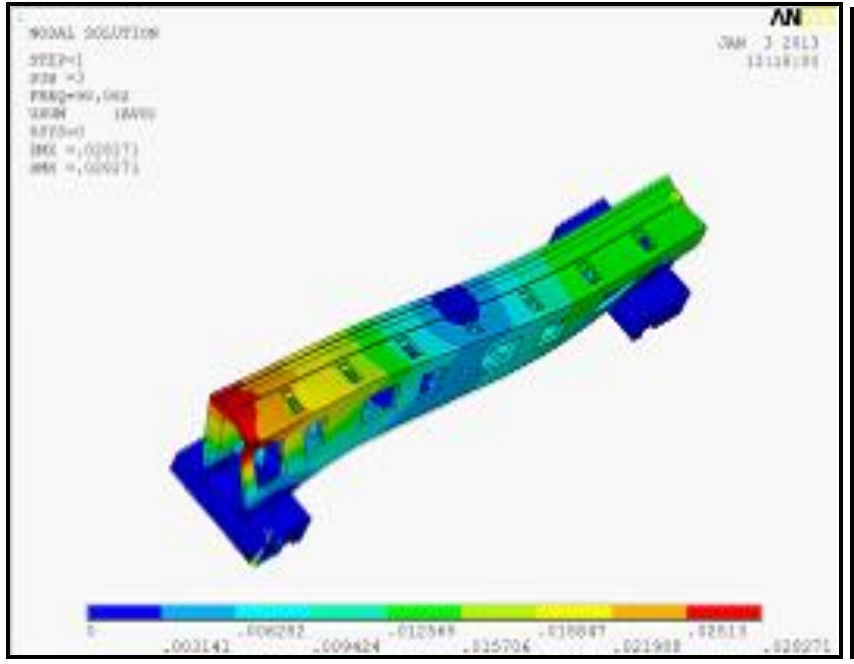

(c) Third-order vibration mode

Fig . (7). Analysis results of the original design cross beam.

are respectively the corresponding modal stiffness and modal mass) [10], the corresponding modal torsion stiffness of the improved cross beam has been significantly increased, so the improved structure has achieved the optimization design of improving the dynamic performance of the cross beam.

\section{CONCLUSION}

(1) Taking the Turning-Milling Compound Machine Center (HTM 50200) for example, this paper discussed the application of topology optimization design on the design of cross beam's craft holes. It established the finite element model of the cross beam and realized the topology optimization of the craft holes. The results shows that topology optimization enable the design of cross beam optimized.

(2) Introduction of topology optimization method in machine design makes the distribution of the each part's material of the cross beam more reasonable. In the case of the weight saving of approximately $2.76 \%$, the maximum de-

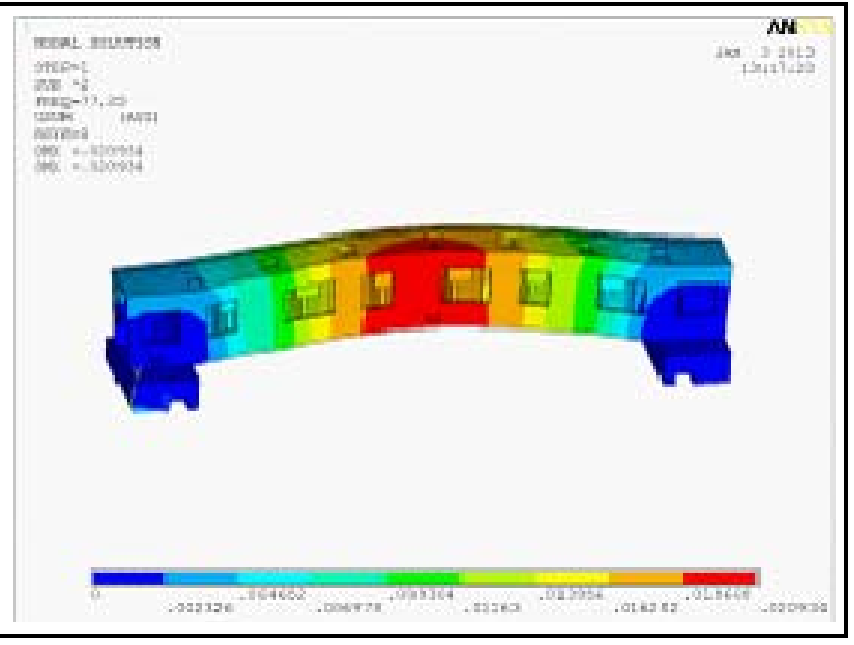

(b) Second-order vibration mode

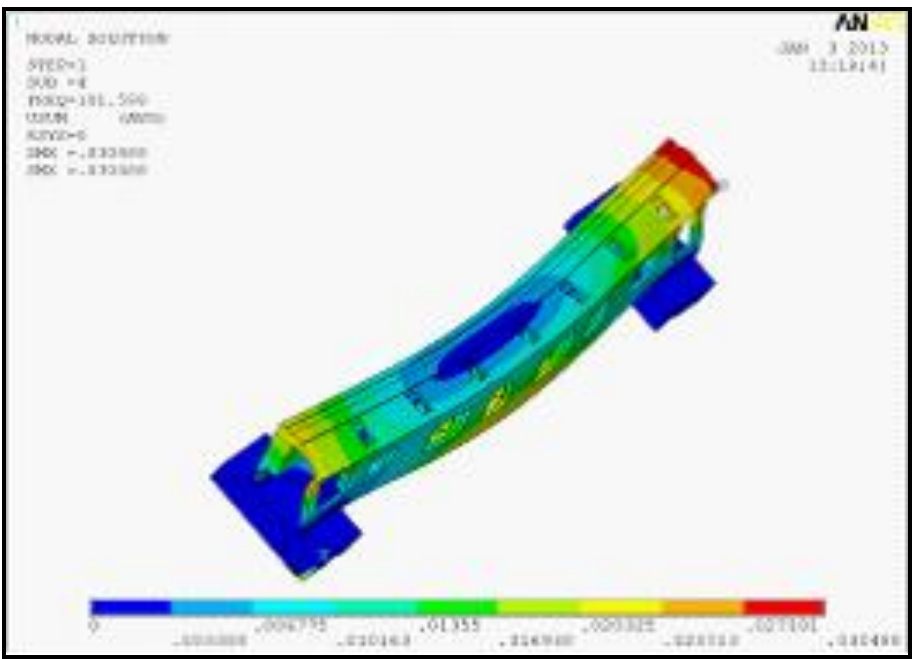

(d) Fourth-order vibration mode

formation achieves a reduction of $16.07 \%$ and the stiffness is improved.

(3) By applying topology optimization method to the design process of the Turning-Milling Compound Machine Center, the material utilization has been improved and the production costs have been reduced.

\section{CONFLICT OF INTEREST}

The authors confirm that this article content has no conflict of interest.

\section{ACKNOWLEDGEMENTS}

This work was financially supported by the Innovation Program of Education Commission supported plan (IRT1160), the Liaoning technology Research plan (2011220012), the Liaoning Natural Science Foundation (20102186), Shenyang Municipal technology Research plan (F12-036-2-00) and Shenyang Jianzhu University Key Laboratory Foundation (JX-200905). 


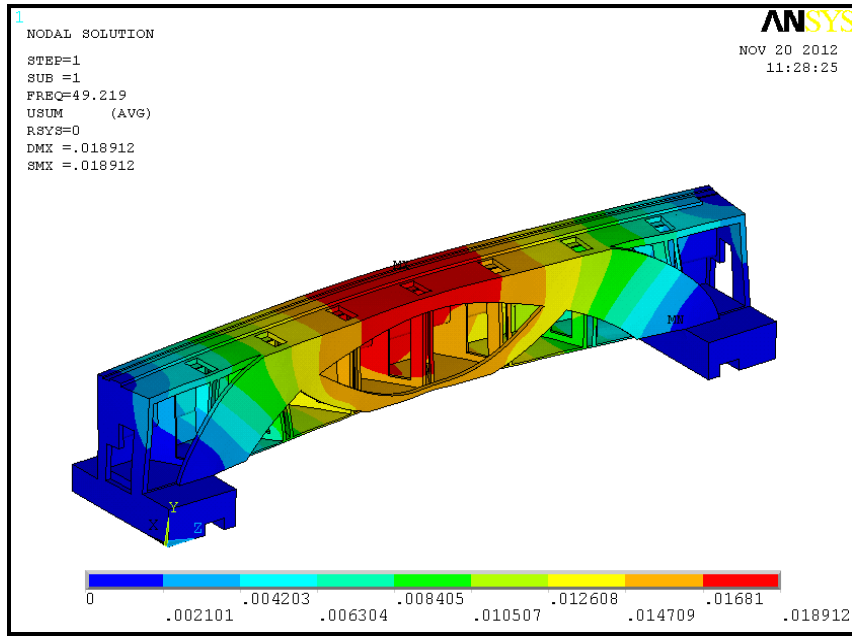

(a) First-order vibration mode

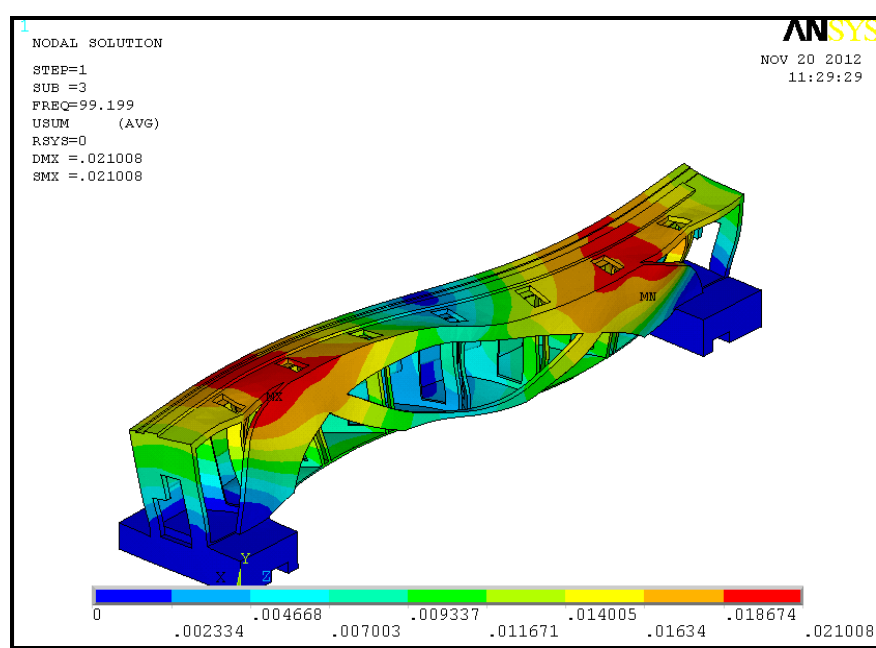

(c) Third-order vibration mode

Fig. (8). Analysis results of the optimized cross beam.

\section{REFERENCES}

[1] D.S. Wang, and B.Q.L. Liu, "Topology optimization design of the model centrifuge gondola", Spacecraft Environment Engineering, vol. 26, pp. 254-258, 2009. (In Chinese)

[2] X.Y. Wang, and Z.Y. Jia, "The topological optimation design and analysis for gantry machine tool crossbeam component", Manufacturing Technology \& Machine Tool, vol. 11, pp. 64-67, 2009, (In Chinese)

[3] X.J. Liu, and L.Z. Dong, Science China Technology Sciences, vol. 54, pp. 1505-1514, 2011.

[4] X. Huang, Z.H. Zuo, and Y.M Xie, "Evolutionary topological optimization of vibrating continuum structures for natural frequencies", Computers and Structures, vol. 88, pp. 357-364, 2010.

[5] S.K. Yang and Q.X. Zhu, "Study on FEM-based topological optimization design of brackets", Automotive Technology, pp. 16-18, 2006. (In Chinese).

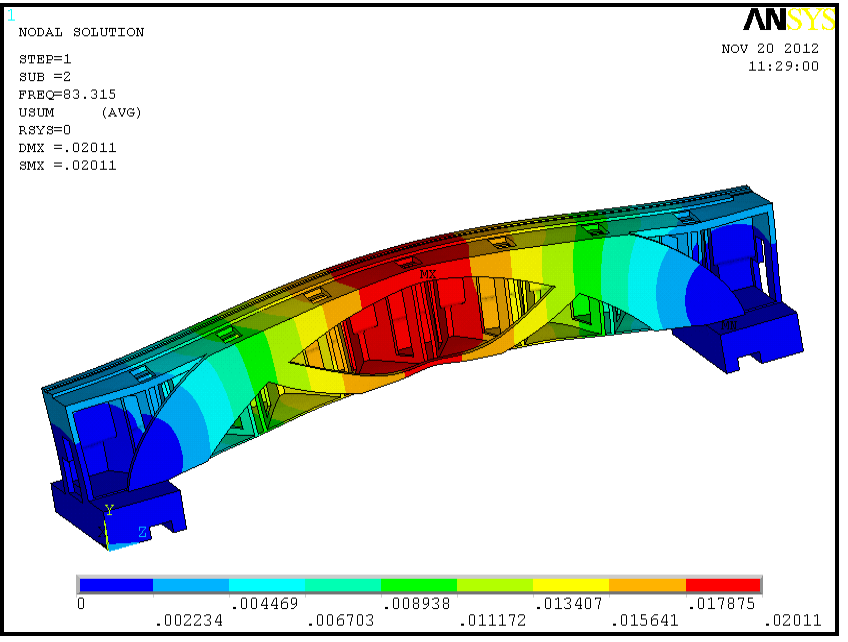

(b) Second-order vibration

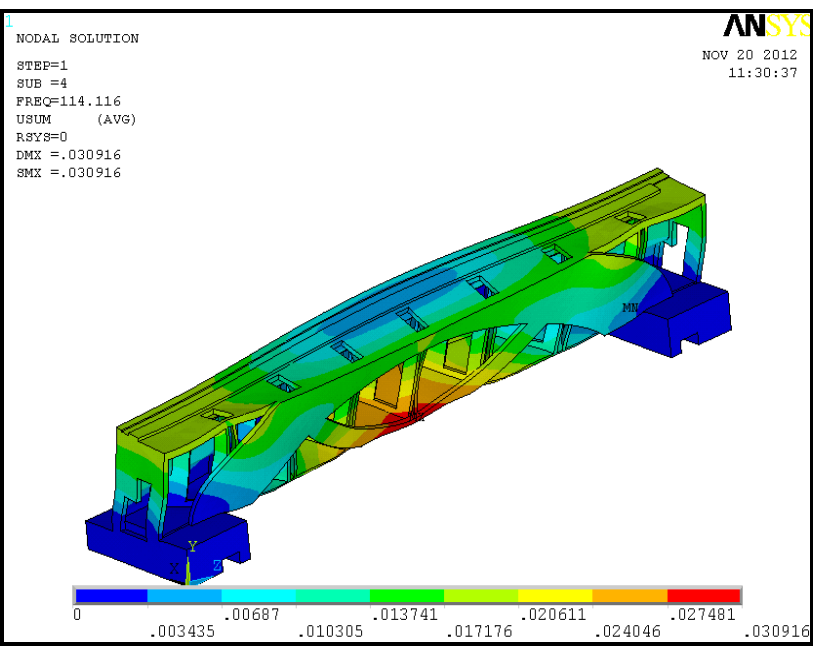

(d) Fourth-order vibration mode

[6] G.T. Yang, Elastoplastic Mechanical Theory, Tsinghua University Publication, China, 2007.

[7] K.T. Zuo, L.P. Chen and Y.Q. Zhang, "The thermal, conduction cooling structure optimized design on topology optimization methods", Chinese Journal of Mechanical Engineering, vol. 41 , pp. 13-17, 2005

[8] Q. Shi, and L.P. Lu, "Based on the finite element analysis of Hood topology optimization design", Machine Design and Manufacture, vol. 6, pp. 31-33, 2009.

[9] Y.H. Wu, G. Wu, and K. Zhang, "Dynamic characteristic analysis on the key component of machining center", Journal of Shenyang Jianzhu University (Natural Science Edition), vol. 25, pp. 165$169,2009$.

[10] F. Li, and J.R. Zhang, "Topology optimization in the beams structure optimization of XH2725 machine tool", Manufacture Information Engineering of China, vol. 36, pp. 48-52, 2007.

\section{(C) Zhang et al.; Licensee Bentham Open}

This is an open access article licensed under the terms of the Creative Commons Attribution Non-Commercial License (http://creativecommons.org/licenses/by-nc/3.0/) which permits unrestricted, non-commercial use, distribution and reproduction in any medium, provided the work is properly cited. 